\title{
Experimental investigation of the behaviour of Unreinforced Masonry strengthened with UHPFRC
}

\author{
Principal Lecturer \\ University of Brighton \\ Brighton, UK \\ a.lampropoulos@brighton.ac.uk
}

Andreas P. LAMPROPOULOS Neil MAISURIA

Dr Andreas Lampropoulos is a Principal Lecturer in Civil Engineering at the University of Brighton in the UK

\author{
MEng Civil Engineering student \\ University of Brighton \\ Brighton, UK \\ n.maisuria1@uni.brighton.ac.uk
}

\author{
Ourania T. TSIOULOU \\ Senior Lecturer \\ University of Brighton \\ Brighton, UK \\ o.tsioulou@brighton.ac.uk
}

Contact: a.lampropoulos@brighton.ac.uk

\section{Abstract}

The majority of existing Unreinforced Masonry (URM) structures are prone to weathering and catastrophic events such as earthquakes. The repair and strengthening of unreinforced masonry is a challenging task mainly due to the poor connection between the new materials and the existing substrate. The applications of Fibre Reinforced Polymers (FRP) for the strengthening of URM show that premature de-bonding and failure of the strengthened elements may occur.

In the current study, the application of Ultra High Performance Fibre Reinforcement Concrete (UHPFRC) layers for the improvement of the structural performance of URM specimens made of engineering bricks has been examined. Different percentages of steel fibres have been used and layers have been cast in connection with the URM specimens. Additional provisions for the improvement of the connection between the UHPFRC and the bricks have also been examined. The effect of the thickness of the layers and the effect of the fibre percentage of the UHPFRC have been investigated via flexural out of plane tests. The load midspan deflection results have been recorded alongside with the slip at the UHPFRC-to-bricks interface and the results show that the structural performance of the URM specimens can be significantly improved with the proposed technique.

Keywords: Masonry; walls; strengthening; UHPFRC.

\section{Introduction}

Unreinforced Masonry (URM) is one of the most commonly used construction types in many areas worldwide including earthquake prone regions. However, the majority of the existing URM structures are prone to seismic loads due to the low tensile strength characteristics of the material and URM elements suffer of significant damages and collapses after earthquakes. Even in cases where URM is not used as the main load bearing elements (e.g. infill walls) the contribution of URM elements to the structural performance of the structures is of high importance and failures or even collapses of these elements may significantly affect the performance of the structures while they can also lead to injuries and fatalities of the occupants. In case of damaged URM elements, it is common practice to demolish and rebuild these elements to avoid brittle type of failures and collapses. In other cases where additional strength is required, various strengthening techniques have been using conventional materials such as Reinforced Concrete (RC) layers or novel materials such as Fibre Reinforced Polymers (FRPs) [1-4]. However, a 
crucial point is the connection between the URM and the additional walls which is normally weak and is a major point of concern.

In the last decade, the development and application of Ultra High Performance Fibre Reinforced Concrete (UHPFRC) has been extensively studied and it has been proved that the application of UHPFRC can considerably enhance flexural and shear strength of existing Reinforced Concrete (RC) elements $[5,6]$. So far there is very a limited research on the use of UHPFRC for the structural upgrade of URM. Numerical studies were recently conducted $[7,8]$ and it was found that the addition of UHPFRC layers can significantly improve the inplane and out-of-plane performance of URM walls. There is only one study so far [9] where the significant contribution of UHPFR layers to the URM has been confirmed and this was conducted on very low strength aerated concrete bricks which were simulating substandard low strength materials used in low and middle income countries.

In this paper the application of UHPFRC layers for the strengthening of URM walls made of engineering bricks has been examined and the efficiency of this method has been evaluated.

\section{Experimental Investigation}

In this section, the geometry and the dimensions of the examined specimens are presented alongside with the material properties and the description of the UHPFRC preparation.

\subsection{Description of the examined specimens and material properties of the URM}

In this study, class b engineering bricks with $50 \mathrm{MPa}$ compressive strength were used for the initial brick walls. The dimensions of the bricks were $65 \mathrm{~mm} x$ $102.5 \mathrm{~mm} \times 215 \mathrm{~mm}$ with $10 \mathrm{~mm}$ mortar joints (Figure 1). For the mortar, cement and sand with by volume ratio 1:4 was used, while the water to cement by weight ratio was equal to 0.5 , representing standard mortar used in masonry walls.

Cubes with $100 \mathrm{~mm}$ side were used to evaluate the mean compressive strength of the mortar which was found equal to $9.36 \mathrm{MPa}$.

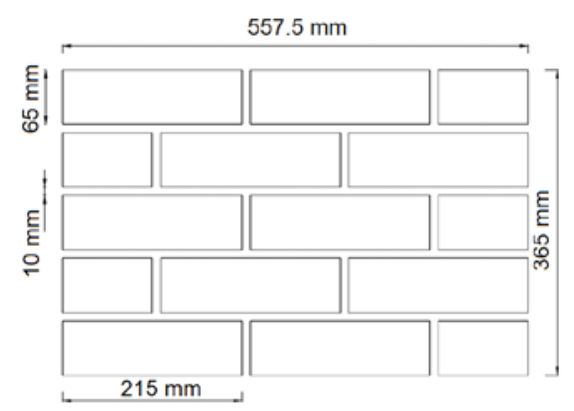

Figure 1. URM walls prior to strengthening

In total, seventeen brick walls were examined in this study and the description of the examined specimens is presented in Table 1.

Table 1. Examined Specimens

\begin{tabular}{llll}
\hline Specimens ID & $\begin{array}{l}\text { Number } \\
\text { of } \\
\text { specime } \\
\text { ns }\end{array}$ & $\begin{array}{l}\text { Thickness of } \\
\text { UHPFRC } \\
\text { layer } \\
(\mathrm{mm})\end{array}$ & $\begin{array}{l}\text { UHPFRC } \\
\text { Fibre } \\
\text { Volume } \\
\text { Fraction } \\
(\%)\end{array}$ \\
\hline URM & 3 & N/A & N/A \\
UHPFRC-10-3\% & 3 & 10 & 3 \\
UHPFRC-30-3\% & 2 & 30 & 3 \\
UHPFRC-30-Rep-3\% & 3 & 30 and & re- \\
UHPFRC-30-1\% & 3 & 30 & 1 \\
UHPFRC-30-6\% & 3 & 30 & 6 \\
\hline
\end{tabular}

Three URM specimens were not strengthened (URM), three specimens were strengthened with $10 \mathrm{~mm}$ layer with $3 \%$ percentage of steel fibres (UHPFRC-10-3\%), two specimens were strengthened with $30 \mathrm{~mm}$ layer with $3 \%$ percentage of steel fibres (UHPFRC-30-3\%), and three specimens were strengthened with $30 \mathrm{~mm}$ layer with $6 \%$ percentage of steel fibres (UHPFRC-30-6\%). For the remaining three specimen a novel application was examined where the existing conventional mortar was removed at a depth equal to the $1 / 3$ of the total thickness of the wall and repointing with UHPFRC was applied in addition to a $30 \mathrm{~mm}$ UHPFRC layer with $3 \%$ fibres (UHPFRC-30Rep-3\%). 
The specimens were strengthened 28 days after the casting of the URM walls and they were cured for another two months at ambient temperature of 21$23^{\circ} \mathrm{C}$ and relative humidity $55-60 \%$. The mix design of the UHPFRC used in this study is presented in Table 2.

Table 2. UHPFC mix design

\begin{tabular}{cc}
\hline Material & $\begin{array}{c}\text { Mix proportions } \\
\left(\mathrm{kg} / \mathrm{m}^{3}\right)\end{array}$ \\
\hline Cement (32.5) & 657 \\
GGBS & 418 \\
Silica fume & 119 \\
Silica Sand & 1051 \\
Superplasticizers & 59 \\
Water & 185 \\
Steel fibers (3\%) & 235.5 \\
\hline
\end{tabular}

Silica sand with maximum particle size of $500 \mu \mathrm{m}$ was initially mixed together with dry silica fume, Ground Granulated Blast Furnace Slag (GGBS), and cement (32.5). After the mixing of the dry materials, water and polycarboxylate superplasticizer were added to the mix followed by gradual addition of straight steel fibres. Two different types of fibres were used in this study. Fibres with $13 \mathrm{~mm}$ length, nominal diameters of $0.21 \mathrm{~mm}$ and tensile strength of $2750 \mathrm{MPa}$ were used for UHPFRC-10-3\% and UHPFRC-30-Rep-3\% while for all the remaining specimens, fibres with $6 \mathrm{~mm}$ length, nominal diameters of $0.15 \mathrm{~mm}$ and tensile strength of 3000 MPa were used.

For the casting of the UHPFRC layers the specimens were placed in the moulds and UHPFRC was poured until various levels depending on the thickness of the layer. Strengthened specimens can be seen in Figure 2.



Figure 2. Strengthened specimens with UHPFRC
This is a process which cannot be applied in practice and the flowability of UHPFRC needs to be adjusted to allow casting of the layers with rendering of the walls in a vertical configuration.

In addition to the brick walls, cubes with $100 \mathrm{~mm}$ side and dog bone shaped specimens with $20 \mathrm{~mm} x$ $14 \mathrm{~mm}$ cross section were examined to evaluate the compressive and tensile properties of UHPFRC.

The testing procedure together with the obtained results are presented in section 3.2.

\subsection{Testing of the specimens and results}

For the testing of the examined brick walls, three point loading testing setup with span length equal to $500 \mathrm{~mm}$ was selected to evaluate the out-ofplane performance of the walls (Figure 3 ).

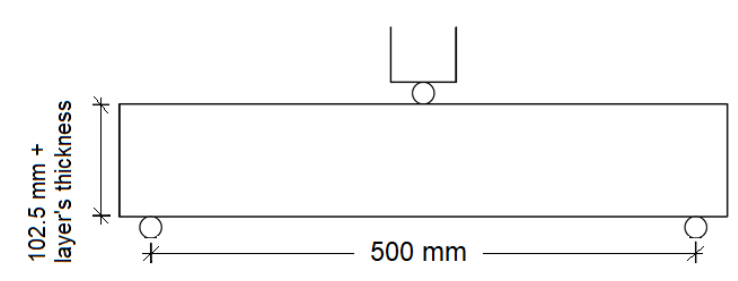

Figure 3. Three point loading testing setup

Displacement control was used for the testing of the walls with a rate of $0.1 \mathrm{~mm} / \mathrm{min}$ and the mid span deflection was measured using two Linear Variable Differential Transformers (LVDTS) in the two sides of the specimens. The load versus mid-span deflection was recorded during the tests, while Digital Image Correlation System was also used to monitor the strains and slips at the interfaces between the UHPFRC and the URM in all the strengthened units (Figure 4).

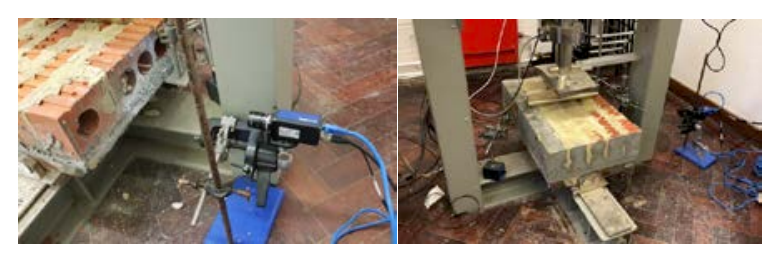

Figure 4. Digital Image Correlation setup for the monitoring of the interface strains

Cubes with $100 \mathrm{~mm}$ side and dog-bone specimens with $14 \mathrm{~mm} \times 20 \mathrm{~mm}$ cross section were also cast and tested at the same age to obtain compressive 
strength and tensile stress-strain characteristics of the UHPFRC. The dog-bone testing of many of the examined samples was unsuccessful either due to local failures near the grips or because of the relatively small dimensions of the examined specimens especially in case of high percentage of steel fibres. From the examined specimens which were successfully tested, the maximum tensile strength was found approximately equal to $4 \mathrm{MPa}$.

Regarding the compressive strength, the mean compressive strength of the UHPFRC with $1 \%$ steel fibres was found equal to $104 \mathrm{MPa}$, while the respective values for $3 \%$ and $6 \%$ fibres content were found equal to $133 \mathrm{MPa}$ and $124 \mathrm{MPa}$.

The obtained values for both tensile and compressive strength characteristics are lower than the values normally expected for UHPFRC and this is attributed to the fact that low strength concrete (32.5) and ambient temperature curing were used in this study.

\section{Results and discussion}

\subsection{Experimental results}

The comparison of the average results of the examined specimens is illustrated in Figure 5.

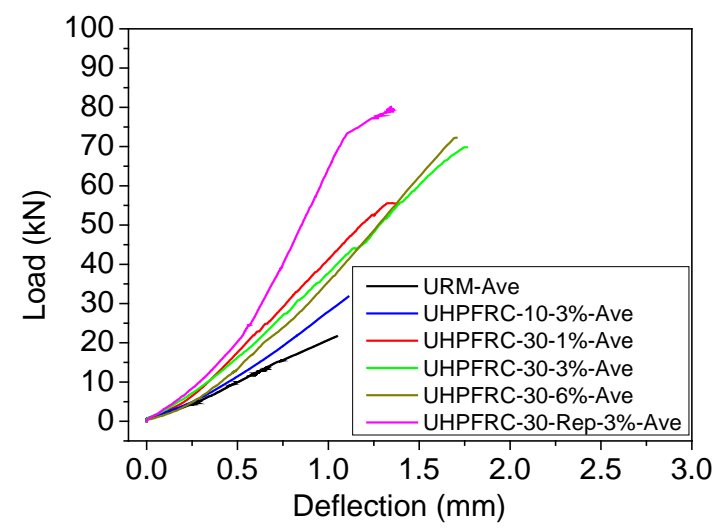

Figure 5. Comparison of the average load deflection results for the various types of specimens

From the results of Figure 5 it is evident that URM specimens failed in a brittle way as expected, while the addition of UHPFRC resulted to significant strength and stiffness increment of the URM specimens.
All URM specimens exhibited brittle failure, with cracks which in most cases started from the mortar joints and then continued to the bricks as expected.

Regarding the strengthened specimens, cracks initiated from the brick walls which were then propagated to the brick-to-UHPFRC interface and then to the UHPFRC layers. The failure mode was similar for all the examined strengthened elements.

The experimental results indicated that there is very good bond at the interface between the bricks and the UHPFRC and perfect connection was observed for all the examined specimens until a point near the failure of the specimens where the cracks were propagated from the bricks to the interface and then to the UHPFRC layer.

The interface of all the strengthened specimens was monitored using a Digital Image Correlation (DIC) system (Figure 4) and the perfect bond between at the interface, up to a load close to the maximum load capacity, was confirmed.

Indicative results for the shear strain distribution of one of the examined UHPFRC-30-3\% specimens is presented in Figure 6.

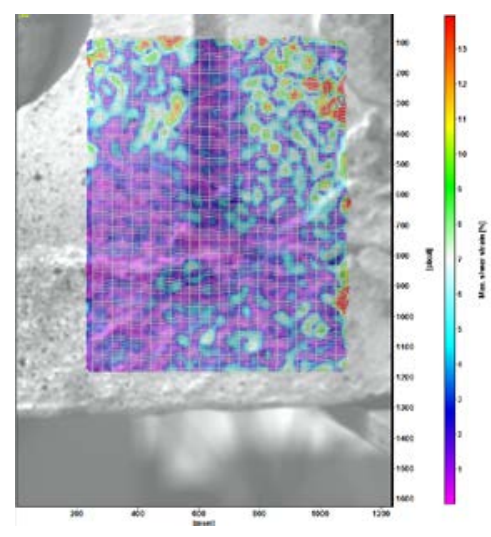

Figure 6. Shear strain distribution at the end of test of one of the UHPFRC-30-3\% specimens

It is evident from Figure 6, that there was not any shear strain concentration at the interface of the examined specimens even at a point near the failure which demonstrates very good interface conditions. Similar behavior was observed for most of the examined specimens and slips and cracks at the interface were only observed at a very late loading stage and at the post peak behavior of the loaddeflection graphs. 
The exact values of the maximum load of all the examined specimens together with the average values are presented in Table 3.

From the results of Table 3 it can be seen that 110\% increment of the maximum load was observed for the specimen strengthened with $10 \mathrm{~mm}$ layer with $3 \%$ fiber percentage (UHPFRC-10-3\%). By increasing the thickness of the layer to $30 \mathrm{~mm}$ (UHPFRC-30$3 \%)$, the increment of the maximum load reached a value of $232 \%$. The use of UHPFRC with $6 \%$ steel fibres and $30 \mathrm{~mm}$ layer (UHPFRC-30-6\%) resulted to even higher load increment and was found equal to $379 \%$ while the partial repointing (1/3 of the joint depth) in addition to $30 \mathrm{~mm}$ thick layer using UHPFRC with $3 \%$ steel fibres resulted to the highest load increment which equals to $388 \%$.

Table 3. Maximum load results for all the examined specimens

\begin{tabular}{llc}
\hline Specimen & $\begin{array}{l}\text { Maximum } \\
\text { load }(\mathrm{kN})\end{array}$ & $\begin{array}{l}\text { Average } \\
\text { load }(\mathrm{kN})\end{array}$ \\
\hline URM-1 & 15.1 & 16.93 \\
URM-2 & 14.02 & \\
URM-3 & 21.66 & \\
UHPFRC-30-1\%-1 & 56.623 & 56.26 \\
UHPFRC-30-1\%-2 & 55.9 & \\
UHPFRC-10-3\%-1 & 33.28 & \\
UHPFRC-10-3\%-2 & 33.9 & 35.55 \\
UHPFRC-10-3\%-3 & 39.48 & \\
UHPFRC-30-3\%-1 & 77.105 & \\
UHPFRC-30-3\%-2 & 61.529 & 70.02 \\
UHPFRC-30-3\%-3 & 71.423 & \\
UHPFRC-30-6\%-1 & 73.421 & \\
UHPFRC-30-6\%-2 & 87.672 & \\
UHPFRC-30-3\%-3 & 82.237 & \\
UHPFRC-30-Rep-3\%-1 & 73.34 & \\
UHPFRC-30-Rep-3\%-2 & 94.49 & \\
UHPFRC-30-Rep-3\%-3 & 80.01 & \\
\hline
\end{tabular}

Analytical calculations of the load increment were also contacted following a simplified cross-sectional analysis which was also conducted in a previous study [9]. The additional moment capacity of the cross section due to the addition of the UHPFRC layer was calculated considering that the load is applied to the middle of the height of the layer (Figure 7).

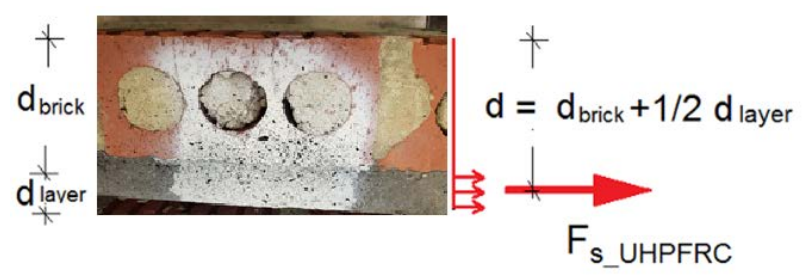

Figure 7. Cross sectional analysis for specimens strengthened with UHPFRC layers

For the repointed specimens (UHPFRC-30-3-REP), the addition of UHPFRC resulted to further enhancement of the tensile side of the walls. For the cross sectional analysis of these specimens, the stress block of the UHPFRC was extended until the point where UHPFRC was used at the joints ( $1 / 3$ of the depth) the internal forces of Figure 8 were used.

The analytical calculations of the additional load were made for UHPFRC-10-3\%, UHPFRC-30-3\% and UHPFRC-30-Rep-3\% considering tensile stress of UHPFRC equal to $4 \mathrm{MPa}$. The comparison between the analytical and experimental results is illustrated in Figure 8.

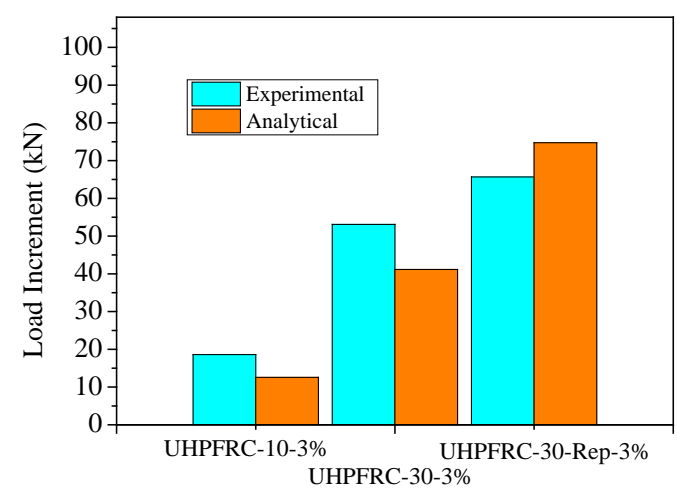

Figure 8. Comparisons between experimental and analytical results

The results indicate that there is quite good agreement between the experimental and analytical results. The assumption of considering extension of the UHPFRC stress block to the repointing depth resulted to calculated values close to the experimental ones. 


\section{Conclusions}

This study was focused on the strengthening of existing engineering brick walls using UHPFRC layers. This technique could be applied either for the structural upgrade of URM structures or even for the conversion of existing infill walls to load bearing walls.

The main findings are summarized below.

- The results of this study show that the UHPFRC layers can considerably improve the structural performance of the URM walls.

- Very good interface conditions were observed between the UHPFRC and the existing brick walls even if there was not any treatment of the surface of the existing walls.

- Partial repointing of the existing mortar in addition to UHPFRC layers was found to further improve the structural performance of the examined specimens.

\section{References}

[1] D. Abrams, T. Smith, J. Lynch, and S. Franklin, "Effectiveness of Rehabilitation on. Seismic Behaviour of Masonry Piers," ASCE Journal of Structural. Enginering, vol. 133(1), pp 32-44, 2007.

[2] N. Galati, G. Tumialan, and A. Nanni, "Strengthening with FRP bars of URM walls subject to out-of-plane loads," Construction and Building Materials, vol. 20(1-2), pp 101110, 2006.

[3] A. Mosallam, "Out-of-plane flexural behavior of unreinforced red brick walls strengthened with FRP composites," Composites: Part B, vol. 38, pp. 559-574, 2007.

[4] P. Roca, G. Araiza, "Shear response of brick masonry small assemblages strengthened with bonded FRP laminates for in-plane reinforcement,". Construction and Building Materials, vol. 24, pp 1372-1384, 2010.

[5] A. Lampropoulos, S. Paschalis, O. Tsioulou, and S. Dritsos, "Strengthening of reinforced concrete beams using ultra high performance fibre reinforced concrete (UHPFRC)," Engineering Structures, vol. 106, pp 370-384, 2016.

[6] M. Bastien Masse, E. Brühwiler, "Contribution of R-UHPFRC Strengthening layers to the shear resistance of $\mathrm{RC}$ elements," Structural Engineering International, vol. 4, pp 365-374, 2016.

[7] A. Lampropoulos, O. Tsioulou, S. Paschalis, and S. Dritsos, "Strengthening of unreinforced masonry structures using Ultra High Performance Fibre Reinforced Concrete (UHPFRC)," $19^{\text {th }}$ IABSE Congress, Stockholm, Sweden, 2016.

[8] A. Lampropoulos, O. Tsioulou, S. Paschalis, and S. Dritsos, "Strengthened Unreinforced Masonry (URM) structures with Ultra High Performance Fibre Reinforced (UHPFRC) layers under axial in-plane and horizontal out-of-plane loading," $39^{\text {th }}$ IABSE Symposium, Vancouver, Canada, 2017.

[9] A. Lampropoulos, A. Tasji, and 0 . Tsioulou, "Structural upgrade of deficient Unreinforced Masonry structures using Ultra High Performance Fibre Reinforced Concrete," $40^{\text {th }}$ IABSE Symposium, Nantes, France, 2018. 